\title{
Using Biebersteinia multifida aqueous extract, and the Photocatalytic Activity of Synthesized Silver Nanoparticles
}

\author{
ABDOLHOSSIEN MIRI ${ }^{1}$, SEYEDEH RAZIYEH MOUSAVI'2, MINA SARANI ${ }^{3 *}$ \\ and ZOHRE MAHMOODI ${ }^{4}$ \\ 'Department of Pharmacognosy, Faculty of Pharmacy, Zabol University of Medical Sciences, Zabol, Iran. \\ 2Department of Horticulture and Landscape, Faculty of Agriculture, University of Zabol, Zabol, Iran. \\ ${ }^{3}$ Zabol Medicinal Plants Research Center, Zabol University of Medical Sciences, \\ P.O. Box, 3333-669699, Zabol, Iran. \\ ${ }^{4}$ Department of Cardiovascular Surgery, Zabol University of medical Science, Zabol, Iran. \\ ${ }^{*}$ Corresponding author E-mail: minasarani64@gmail.com \\ http://dx.doi.org/10.13005/ojc/340342
}

(Received: August 31, 2017; Accepted: February 22, 2018)

\begin{abstract}
Now a days synthesis of nanoparticles using plants and herbal products is significant by the many researchers. In this study, we report the synthesis of silver nanoparticles (Ag NPs) using aqueous extract of Biebersteinia multifida at room temperature and its photocatalytic activity for degradation of methyl blue (MB) dye under visible light. The synthesized nanoparticles were characterized by using UV-Vis spectroscopy, powder X-ray diffraction (PXRD) and transmission electron microscopy (TEM). Synthesized nanoparticles are spherical with $57 \mathrm{~nm}$ of particle size. Results photocatalytic activity of synthesized Ag NPs showed that degradation efficiency arrived to $92 \%$ in first 30 minutes.
\end{abstract}

Keywords: Ag NPs, B. multifida, Green synthesis, Methyl blue, Photocatalytic.

\section{INTRODUCTION}

Silver nanoparticles (Ag NPs) are considered vital in medicine and industry; therefore they are utilized for purposes such as antiseptics, covering medical instruments ${ }^{1-5}$, biosensors ${ }^{6}$, gene and drug carriers ${ }^{7,8}$, catalysis and electrical conductance $^{9}$. The biologic and catalysis activity of Ag NPs depended on its specific surface area'. Due to the widespread use of Ag NPs, many different methods for their synthesis have been reported including gamma rays ${ }^{10}$, ultraviolet rays ${ }^{11}$, electrochemical reduction ${ }^{12}$, and reducing agents such as sodium boron hydride $\left(\mathrm{NaBH}_{4}\right)^{13,14}$, which are mostly expensive, toxic, time-consuming, and require special equipments. Since it can be concluded that a low cost, quick, and environmentally friendly method is needed for the synthesis of Ag NPs, using plants for this purpose would be a desirable suggestion.

This is an Open Access article licensed under a Creative Commons Attribution-Non Commercial-Share Alike 4.0 International License (https://creativecommons.org/licenses/by-nc-sa/4.0/), which permits unrestricted Non Commercial use, distribution and reproduction in any medium, provided the original work is properly cited. 
Biebersteinia multifida DC (Geraniaceaae family) is a native plant of Iran, also called Chele Daq and Adamak, but grows in Syria, Armenia, Afghanistan, Lebanon and Central Asia as well ${ }^{15}$. Its active ingredients are Alkaloids, polysaccharides, polypeptides and Flavonoids such as Apigenin, Luteolin, and Tricetin that have antioxidant and antimicrobial effects ${ }^{16}$. Recent studies on B. multifida essential oil have indicated on the existence of $(\mathrm{E})$-nerolidol ${ }^{17}$. Due to the existence of the mentioned compounds, it is likely that $B$. multifida is capable of reducing metal ions and thus, it was utilized for the synthesis of Ag NPs.

Dyes use widely at industries and daily life in textile, paper and plastics and they enter to the environment and pollution it. So, dyes pollution is one of the challenges for researchers to eliminate them. The common methods used to remove industrial dyes are electro-coagulation, carbon sorption, redox treatment, flocculation, UV photo-degradation ${ }^{18}$. Reports have shown that metallic nanoparticles can act as photocatalytic agents ${ }^{19-21}$. Therefore, in the study we were investigated photocatalytic activity of synthesized Ag NPs using B. multifida extract on MB dye.

\section{MATERIALS AND METHODS}

\section{Preparation of B. multifida extract}

The root bark of $B$. multifida was collected from Borujen, Chaharmahal and Bakhtiari, Iran, in the spring of 2015. It was dried in shadow. The herbarium code 42094 was allocated to it by Herbarium of the Ferdowsi University of Mashhad (FUHM). The sample was extracted by using Maceration method. $10 \mathrm{~g}$ of the sample was weighed and $100 \mathrm{ml}$ of distilled water was added to it. Then it was placed on a rotating shaker at $100 \mathrm{rpm}$ for 6 hours. The crude extract was filtered by filter Whatman No.1 and the result (yellow solution) was kept in refrigerator with a temperature of $4-7{ }^{\circ} \mathrm{C}$ for the following steps.

\section{Preparation of Ag NPs}

Silver nitrate solution was added to the aqueous extract of $B$. multifida and the solution was shaken at $100 \mathrm{rpm}$ for the defined time and temperature. The formation of a dark brown solution indicated that Ag NPs are produced. In this regard, the four parameters including volume of extract, salt concentration, temperature, and time on the formation of nanoparticles were analyzed. Thorough out all the tests, only one parameter was variable and the rest were fixed.

\section{Photocatalytic activity of Ag NPs}

In order to survey photocatalytic activity of Ag NPs, $25 \mathrm{mg}$ of synthesized Ag NPs was added to $25 \mathrm{ml} \mathrm{MB}$ solution $(15 \mathrm{mg} / \mathrm{l})$. The mixture was stirred constantly for $30 \mathrm{~min}$. in darkness to ensure constant equilibrium of Ag NPs in the organic solution. Then, the suspension was put under the visible light. In the periods of $30 \mathrm{~min} ., 3 \mathrm{ml}$ of suspension was centrifuged at $4000 \mathrm{rpm}$ for $5 \mathrm{~min}$. and absorbance spectrum of the solution was measured using a UV-Visible spectrophotometer. The percentage degradation of MB was analyzed using below equation:

$$
\% \text { Degradation }=\frac{C_{0}-C_{t}}{C_{0}} \times 100
$$

$\mathrm{C}_{0}$ is initial concentration of dye solution and $\mathrm{C}_{\mathrm{t}}$ is the concentration of dye solution after exposure to the visible light.

\section{Characterization of Ag NPs}

Electronic spectra in the visible and ultraviolet regions were recorded in water as solvent through the use of UV-Vis Spectrophotometer (Rayleighuv-2100 model, made in China). Powder $X$-ray diffraction (PXRD) of synthesized nanoparticles was recorded by utilizing the XRD device (X'Pert PRO MPD PANalytical Company model, made in Netherland). The image of nanoparticles was presented through the use of transmission electron microscopy (TEM) (Zeiss EM900 model, made in Germany).

\section{RESULTS AND DISCUSSION}

The basis of synthesizing nanoparticles would be ion reduction and neutralizing the electric charge of particles. The changing color of solution from yellowish orange to brown indicates the formations of colloidal suspension of Ag NPs, which is due to silver ion reduction.

\section{UV-Vis spectroscopy}

UV-Vis spectroscopy is a vital method to determine the formation and stability of metal nanoparticles in an aqueous solution ${ }^{22}$. The Ag NPs show their highest peak of UV-Vis absorption in the 
range of $400-500 \mathrm{~nm}^{23}$. The position and shape of the plasmon absorption depends on the size and shape of the particles and dielectric constant of its surrounding area ${ }^{24}$. A peak in the region of $427 \mathrm{~nm}$ was observed in the UV-Vis spectrum of synthesized Ag NPs, which indicates on the formation of Ag NPs (Figure 1).

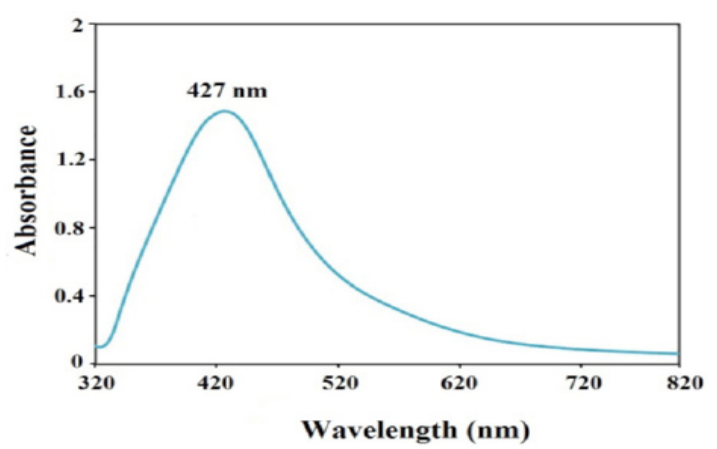

Fig. 1. UV-Vis spectrum of synthesized Ag NPs ( $1 \mathrm{mM}$ of $\mathrm{AgNO}_{3}$ concentration, $5 \mathrm{ml}$ of $B$. multifida extract, at room temperature, 1 hour)

The effects of $\mathrm{AgNO}_{3}$ concentrations (0.5, 1 , and $3 \mathrm{mM}$ ) on the synthesis of Ag NPs in $5 \mathrm{~mL}$ of aqueous extract of the plant were analyzed for $1 \mathrm{~h}$ at room temperature. The maximum absorption bands of synthesized Ag NPs via silver nitrate concentrations of $0.5,1$, and $3 \mathrm{mM}$ appeared in ranges of 464,435 and $440 \mathrm{~nm}$, respectively (Fig. 2). The survey of spectra have shown that with increasing the concentration of silver nitrate salt, the conversions of $\mathrm{Ag}^{+}$to

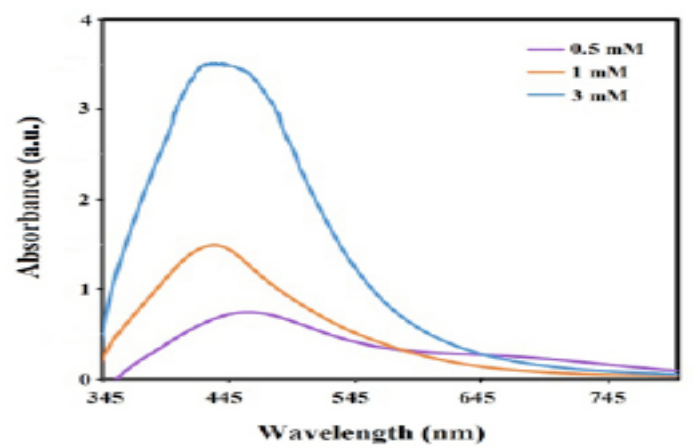

Fig. 2. UV-Vis spectra of Ag NPs at different concentrations of $\mathrm{AgNO}_{3}$

$\mathrm{Ag}^{0}$ increase as well and thus, the peak intensity increase and the solution color become heighten. Increasing $\mathrm{Ag}^{\circ}$ concentration can cause increasing in particle diameter, which would result in increasing absorption ${ }^{25}$.
Through analyzing the effects of aqueous extract volume on Ag NPs synthesis, it was observed that by increasing the volume of extract, peak intensity increased as well and the spectrum got a blue shift (Fig. 3). The plant extract contains organic materials that act as reducing agents and particles stabilizer. When the extract volume increases, nanoparticles get surrounded with higher amounts of organic materials and the particles become heavier, so they settle and lose their nano form; therefore, it was perceived that the absorption intensity decreased by increasing the extract volume to $20 \mathrm{ml}$. Considering the observations, the most suitable extraction volumes would be 3 and $5 \mathrm{ml}^{26,27}$.

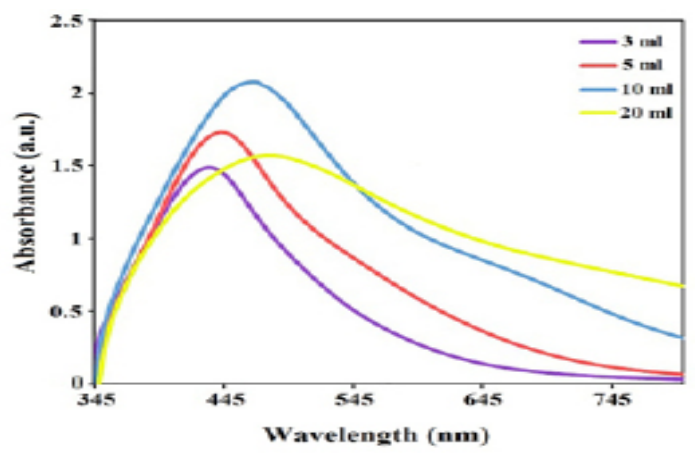

Fig. 3. UV-Vis spectra of Ag NPs at different volumes of B. multifida

The effects of reaction temperature $(20,40$ and $60^{\circ} \mathrm{C}$ ) on the formation of Ag NPs (concentration of $1 \mathrm{mM}$ and $1 \mathrm{~h}$ ) suggest that by increasing the temperature, peak intensity increases as well and shifts toward lower wavelengths; therefore, there were probably more nanoparticles synthesis or the diameter of synthetic nanoparticles were increased (Figure 4) ${ }^{26}$.

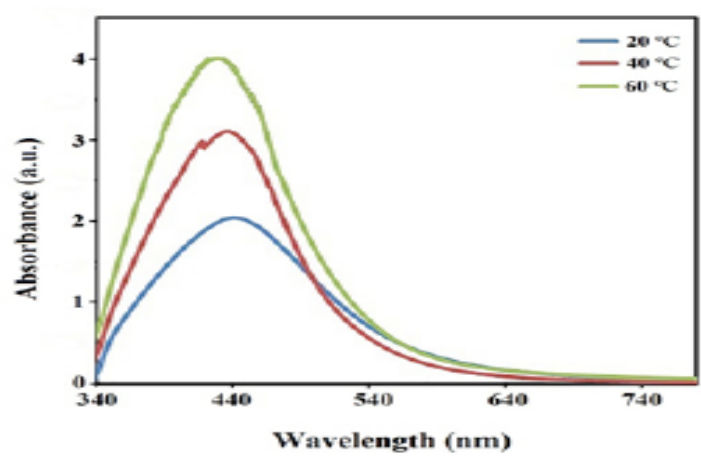

Fig. 4. UV-vis spectra of Ag NPs at different temperatures 


\section{PXRD analysis}

The powder X-ray diffraction (PXRD) of Ag NPs at a silver nitrate concentration of $1 \mathrm{mM}$ and $5 \mathrm{~mL}$ of aqueous extract, for the duration of $1 \mathrm{~h}$ at room temperature, is presented in Fig. 5. This graph demonstrates 5 types of peaks at values of $041 / 38^{\circ}, 3 / 44^{\circ}, 5 / 64^{\circ}$ and $66 / 77^{\circ}, 79 / 85^{\circ}$ in accordance with surfaces of (111), (200), (220), and (311) respectively ${ }^{28,29}$. The peak observed in PXRD graph confirms the crystalline structure of nanoparticles. Moreover, the additional peaks that have appeared in this spectrum are silver chloride ${ }^{28}$. This figure illustrates a centered cubic structure for synthesized Ag NPs.

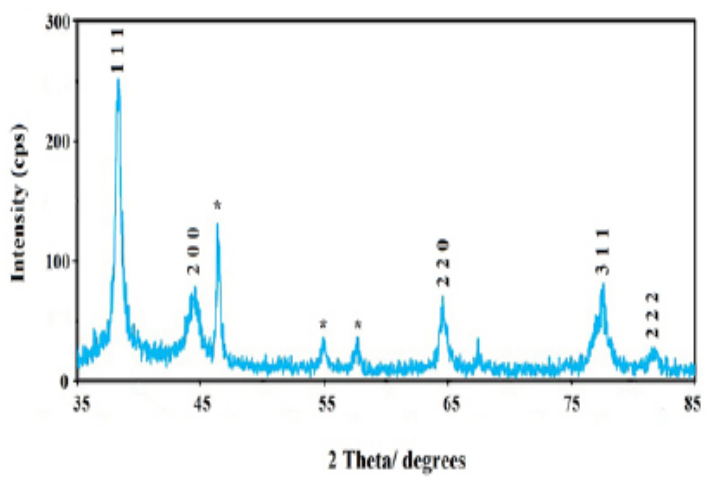

Fig. 5. PXRD spectrum of synthesized Ag NPs with B. multifida extract

\section{TEM image}

The TEM image of synthesized Ag NPs illustrate that they are equal in size according to nanoscale and uniformed in shape. Also, the image demonstrates that in optimal conditions, the particles size of synthesized Ag NPs is $57 \mathrm{~nm}$ (Fig. 6). The TEM image shows that synthesized nanoparticles have spherical shapes.

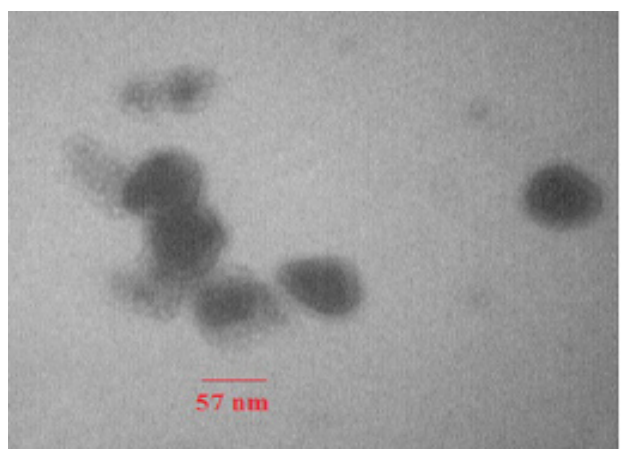

Fig. 6. TEM image of synthesized Ag NPs $\left(1 \mathrm{mM}\right.$ of $\mathrm{AgNO}_{3}, 5 \mathrm{ml}$ of $B$. multifida extract at room temperature, 1 hour)

\section{Photodegradation activity of MB}

Photocatalytic activity of the prepared Ag NPs was surveyed using MB degradation model. $\mathrm{MB}$ is an aromatic dye that dissolves in water and has UV-Vis absorption peak at $665 \mathrm{~nm}$. The intensity of $\mathrm{MB}$ absorption is related to the concentration of MB. After reaction the reduction of MB causes decreasing of the absorption intensity. The result showed (Fig. 7) rapid decrease in MB color from 0 to $30 \mathrm{~min}$., which become slower after $30 \mathrm{~min}$. so that degradation efficiency arrived to $92 \%$ in first 30 minutes. Elemike et al was suggested the mentioned behavior is attributed to the porosity of $\mathrm{Ag}$ $\mathrm{NPs}^{30}$. Chen et al was reported that Ag NPs obtained using $\mathrm{M}$. tinctoria degrade $29.5 \% \mathrm{MB}$ in $24 \mathrm{~h}^{31}$ and also, Elemike et al., was reported it $68.7 \%^{30}$. In compared with mentioned report Ag NPs synthetized using $B$. multifida is more effective, so it has high porosity and can act as good electron donor.

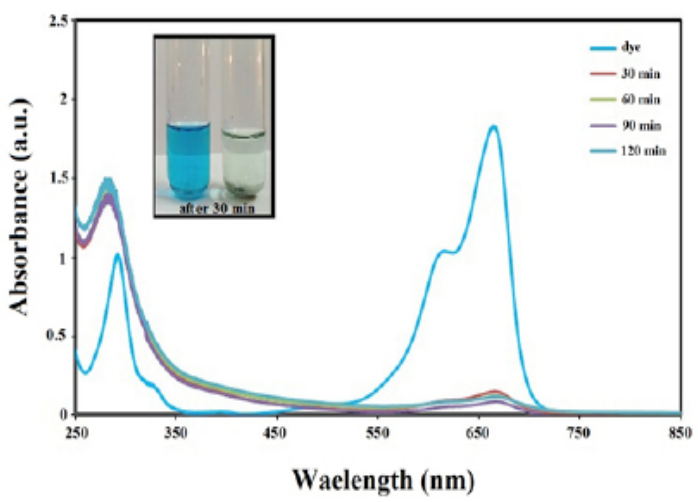

Fig. 7. Photocatalytic degradation of MB using Ag NPs synthesized by B. multifida

\section{CONCLUSION}

Silver nanoparticles are widely used in industrial and medical applications. The antibacterial properties of these particles have caused a revolution in medical science. They are utilized in healing wounds and injuries, as well as in the preparation of dressings, creams and covering medical devices such as catheters, artificial teeth, and surgical masks. Therefore, considering the needs of nanoparticles in medicine and industry, proposing a cheap, easy, quick, accessible, and non-polluting method to synthesize nanoparticles is a necessity. "Green" synthesis is a desirable method to prepare nanoparticles since it meets all of the mentioned demands. The results of this study showed that the aqueous extract of B. multifida root bark, as a reducing agent of silver 
ion, can synthesis nanoparticles in a short time with sizes less than $57 \mathrm{~nm}$; while further studies displayed the good photocatalytic properties of the synthesized nanoparticles.

\section{REFERENCES}

1. Gauger, A.; Mempel, M.; Schekatz, A.; Schäfer, T.; Ring, J.; Abeck, D. Dermatology., 2003, 207, 15-21.

2. Rupp, E.M.; Fitzgerald, T.; Marion, N.; Helget, V.; Puumala, S.; Anderson, J.R.; Fey, P.D. Am $J$ Infect Control., 2004, 32, 445-450.

3. Monteiro, D. R.; Gorup, L. F.; Takamiya, A. S.; Ruvollo-Filho, A. C.; de Camargo, E. R.; Barbosa, D. B. Int J Antimicrob Agents., 2009, 34, 103-110.

4. Khatami, M.; Mehnipor, R.; Sobhani Poor M. H.; Jouzani, G.S. J Clust Sci., 2016, 27(5), 1601-1612.

5. Khatami, M.; Pourseyedi, S. IET Nanobiotechnol., 2015, 1-7.

6. Xia, N.; Chen, Z.; Liu, Y.; Ren, H.; Liu, L. Sens Actuators B Chem., 2017, 243, 784-791.

7. Kasyanenko, N.; Bakulev, V.; Perevyazko, I.; Nekrasova, T.; Nazarova, O.; Slita, A.; Zolotova, Y.; Panarin, E. J Biotechnol., 2016, 236, 78-87.

8. Kumar, C.G.; Poornachandra, Y. Colloids Surf B Biointerfaces., 2015, 125, 110-119.

9. Tahir, K.; Nazir, S.; Li, B.; Khan, A.U.; Haq Khan, Z.U.; Ahmad, A.; Khan, Q.U.; Zhao, Y. J Photochem Photobiol B., 2015, 153, 261-266.

10. Ali, I.; Akl, M.R.; Meligi, G.A.; Saleh, T.A. Results in Physics. 2017, 7, 1319-1328.

11. Lei, Y.; Gao, G.; Liu, W.; Liu, T.; Yin, Y. Appl Surf Sci. 2014, 317, 49-55.

12. Thuc, D.T.; Huy, T.Q.; Hoang, L.H.; Tien, B.C.; Chung, P.V.; Thuy, N.T.; Le, A.T. Mater Lett. 2016, 181, 173-177.

13. Manivel, P.; Balamurugan, A.; Ponpandian, N.; Mangalaraj, D.; Viswanathan, C. Spectrochim Acta A Mol Biomol Spectrosc., 2012, 95, 305-309.

14. Harish, B.S.; Uppuluri, K.B.; Anbazhagan, V. Carbohydr Polym., 2015, 132, 104-110.

15. Golshan, A.R.; Hassanzadeh, S.; Mojdekanloo, M.; Tayarani-Najaran, Z. Avicenna J Phytomed.,
2016, 6, 671-677.

16. Greenham, J.; Vassiliades, D.D.; Harborne, J.B.; Williams, C.A.; Eagles, J.; Grayer, R.J.; Veitch, N.C. Phytochemistry., 2001, 56, 87-91.

17. Monsef-Esfahani, H.R.; Amini, M.; Goodarzi, N.; Saiedmohammadi, F.; Hajiaghaee, R.; Faramarzi, M.A.; Tofighi, Z.; Ghahremani, M.H. Daru. 2013, 21.

18. Roy, K.; Sarkar, C.K.; Ghosh, C.K. Spectrochim Acta A Mol Biomol Spectrosc., 2015, 146, 286-291.

19. Suvith, V.S.; Philip, D. Spectrochim Acta A Mol Biomol Spectrosc., 2014, 118, 526-532.

20. Saoud, K.; Alsoubaihi, R.; Bensalah, N.; Bora, T.; Bertino, M.; Dutta, J. Mater Res Bull., 2015, 63, 134-140.

21. Hosseini, S.J.; Aghaie, H.; Ghaedi, M. Orient.J.Chem., 2014, 30(4), 1883-1895.

22. Naraginti, S.; Sivakumar, A. Spectrochim Acta A Mol Biomol Spectrosc., 2014, 128, 357-362.

23. Dyrba, M.; Miclea, P.T.; Schweizer, S. Radiat Meas., 2010, 45, 314-316.

24. Guzman, M.; Dille, J.; Godet, S. Nanomedicine., 2012, 8, 37-45.

25. Xu, W.; Jin, W.; Lin, L.; Zhang, C.; Li, Z.; Li, Y.; Song, R.; Li, B. Carbohydr Polym., 2014, 101, 961-967.

26. Khalil, M.M.H.; Ismail, E.H.; El-Baghdady, K.Z.; Mohamed, D. Arabian J Chem., 2014, 7, 1131-1139.

27. Ahmed, S.; Saifullah, Ahmad, M.; Swami, B.L.; Ikram, S. J Radiat Res Appl Sci., 2016, 9, 1-7.

28. Miri, A.; Sarani, M.; Rezazade Bazaz, M.; Darroudi, M. Spectrochim Acta A Mol Biomol Spectrosc., 2015, 141, 287-291.

29. Miri, A.; Dorani, N.; Darroudi, M.; Sarani, M. Cell Mol Biol., 2016, 62, 46-50.

30. Elemike, E.E.; Onwudiwe, D.C.; Ekennia, A.C.; Ehiri, R.C.; Nnaji, N. J. Mater Sci Eng C., 2017, 75, 980-989.

31. Chen, Y.; Li, N.; Zhang, Y.; Zhang, L. J Colloid Interface Sci., 2014, 422, 9-15. 